\title{
Reorganizing Medicare for Older Adults with Chronic Illness
}

\author{
Timothy P. Daaleman, DO, MPH
}

\begin{abstract}
A major challenge for the US health care system during coming years will be the financial viability and reorganization of Medicare-a program in which over $90 \%$ of family physicians participate. Although chronic illness constitutes a trajectory characterized by long-term patterns of health and functional states, fee-for-service Medicare is largely directed to the treatment of acute, episodic illness. Beyond the prescription drug benefit, there were several provisions in the Medicare Prescription Drug Improvement and Modernization Act of 2003 that were designed to improve the quality of care and reduce costs for chronically ill beneficiaries, an important first step in the reorientation of Medicare to chronic illness care. Quality is the foundation of Medicare's movement to a chronic care program and paying physicians for quality care is on the horizon. Family physicians will need to be actively engaged in Medicare's reorientation by articulating and promoting a quality of care that effectively integrates evidencebased medicine with a person-centered focus. (J Am Board Fam Med 2006;19:303-9.)
\end{abstract}

Family physicians and other primary care physicians are major stakeholders in the delivery of chronic illness care; care that is largely organized and administered through the Medicare program. ${ }^{1}$ Currently, the American Academy of Family Physicians is supporting the repeal of a $4.3 \%$ reduction in Medicare fee-for-service payments to physicians, scheduled to take effect in early $2006 .^{2}$ By urging Academy members and Congress to rescind the sustainable growth rate formula, which sets a target for growth in Medicare expenditures for physician services based on the growth of the national economy, the American Academy of Family Physicians is seeking to replace it with a payment system based on increases in the practice expenses of physicians. ${ }^{2,3}$ However, there is bipartisan consensus for tying any changes in the sustainable growth rate calculation-a potential increase in Medicare physician reimbursement from $2 \%$ to $3 \%$ each year

Submitted 12 May 2005; revised 19 October 2005; accepted 21 October 2005.

From the Department of Family Medicine, Program on Aging, Disability and Long-Term Care, Cecil G. Sheps Center for Health Services Research, University of North Carolina at Chapel Hill.

Funding: National Institute on Aging [1K23 AG01033] and The Fetzer Institute.

Conflict of interest: none declared.

Corresponding author: Timothy P. Daaleman, DO, MPH, Department of Family Medicine, University of North Carolina at Chapel Hill, Campus Box 7595, Manning Drive, Chapel Hill, NC 27599-7595 (E-mail: tim_daaleman@med.unc.edu). over the next 10 years-to new requirements designed to promote the quality of physician care for chronic illness. $^{3}$

The traditional, fee-for-service Medicare program predominates the organization and financing of chronic illness care in the United States, ${ }^{4}$ and the anticipated economic costs to sustain this program over the next 30 years are staggering as the population continues to age. In 2000, 4.2 million Americans were 85 or older, but by 2030 - the time that the baby-boom cohort will begin to reach age $85-$ nearly 9 million will be over the age of $85 .^{5}$ In addition to the demographic challenges of funding the general needs of an aging population, health care costs are expected to rise faster than the wages paid per worker into Social Security and Medicare, and the long-range costs for Medicare are projected to increase rapidly because of increased use and costs associated with serving a chronically ill population. ${ }^{6}$

A major challenge for the US health care system during the coming years will be the financial viability and reorganization of Medicare-a program in which over $90 \%$ of family physicians participate ${ }^{7}$-from a fee-for-service reimbursement system into a high-quality program of chronic illness care. $^{8}$ This article examines the organization of physician services for chronically ill older adults provided through the traditional Medicare pro- 
gram. First, I provide an overview to the social, demographic, and health service influences that impact the experience of chronic illness in the United States. Next, I briefly review the history of Medicare, and describe 2 provisions within the Medicare Prescription Drug Improvement and Modernization Act (MMA) of 2003, a sentinel step in the reorientation of Medicare to chronic illness care. ${ }^{9}$ Finally, I introduce the Quality Improvement Roadmap, a recently released report by the Centers for Medicare and Medicaid Services (CMS), ${ }^{10}$ and use this report to map out how the reorganization of Medicare will potentially affect family physicians and other primary care providers.

\section{The American Experience of Chronic Illness}

The demographic shift to an older population in the United States has resulted in increased life expectancy ${ }^{11}$ but has also greatly transformed the illness experience. In 1900, the average life expectancy at birth was 47 years; by 1995, the estimated life expectancy reached 75.8 years. ${ }^{12}$ Over 100 years ago, communicable diseases-tuberculosis, diphtheria, and influenza-were the leading causes of death that largely contributed to infant and child mortality rates. ${ }^{13}$ The advent of antimicrobial therapy and major public health initiatives, such as vaccination, reduced mortality in these early years of life. As a result, diseases of chronicity-heart disease, cancer, stroke, and lung disease- - have displaced acute infectious diseases as the major causes of morbidity and mortality today. ${ }^{14,15}$

The experience of serious illness, and subsequently death and dying, has also been transformed from one that was once early in life, rapid, and largely unanticipated, into an ongoing series of events that are chronic and progressive. Heart disease, cancer, lung disease, and stroke have become the most prevalent serious health conditions, accounting for $70 \%$ of all deaths. ${ }^{14,15}$ These diseases disproportionately affect older adults with approximately $80 \%$ of elders reporting at least one chronic condition resulting in pain and disability, loss of function, or limited activity. ${ }^{16}$ The term "serious and eventually fatal chronic illness" has been introduced to describe a subset of chronic diseases that comprise organ system failures (eg, heart, lung, kidney), cancers, and stroke, which are marked by a progressive loss in health and functional status until death occurs. ${ }^{5}$ In contradistinction, other common, nonfatal chronic conditions, such as arthritis, hearing or vision loss, although disabling, rarely result in death. ${ }^{5}$

The concept of trajectory was introduced by sociologist Anselm Strauss over 30 years ago to capture and describe the experience of chronic illness. ${ }^{17}$ Illness trajectory goes beyond depicting the physiologic unfolding of disease, and also encompasses the total organization of work done over the course of the illness, and the impact that this work has on those involved in the work and its organization. ${ }^{17}$ Work connotes the physical and emotional tasking performed by patients and by those who care for them. Within life-course theory, trajectories, as well as transitions and turning points, are also core concepts. Trajectories are sequences or long-term patterns within a focal area (eg, health, family, or work situations) and are formed by examining states (eg, health status, disability) and transitions across successive years. ${ }^{18}$ Trajectories are not individual events in time but are embedded in social pathways that are defined by social institutions and relationships that provide social support. The concept of dying trajectories, for example, has received renewed attention in understanding and improving end-of-life care. ${ }^{19}$ Four dying trajectories—sudden death, terminal illness, organ failure, and frailty-vary in the timing and progression of health events, such as functional decline, but collectively, they depict the last phase of life for most persons. ${ }^{12}$

From an economic perspective, there are wide regional differences in Medicare spending for chronic illness, largely explained by patterns of care that are inpatient and specialty based. ${ }^{20,21}$ There are both compositional and contextual explanations for the variations found here; a compositional explanation attributes variation to differences in the characteristics of persons in defined areas. ${ }^{22}$ For example, a larger concentration of frail, older adults in one geographic area would explain a higher rate of health service use when compared with another area. Contextual explanations, in contrast, suggest that there are features of the social and physical environment that influence the health of those exposed to it. ${ }^{22}$

Intuitively, older adults residing in areas with high concentrations of health care resources (ie, hospitals, physicians) would expect better health outcomes than residents in low resource areas. However, Medicare recipients in high-spending areas do not display better quality of care or improved health outcomes, such as decreased mortal- 
ity or improved functional status, when compared with lower-spending regions. ${ }^{20,23}$ Dramatic differences are, however, found in services provided among patients in the last 6 months of their life, with intensive care unit days being 2.28 times higher in the highest area compared with the lowest. ${ }^{20}$ The local supply of specialist physicians and hospital resources is a major driving force to the use of discretionary services, such as hospitalizations and physician visits, in a defined geographic area. ${ }^{20}$

From this overview, the experience of chronic illness in America can be framed by several perspectives. First, chronic illness constitutes a trajectory, rather than a series of discrete illness events, that is characterized by long-term patterns of health and functional states punctuated by acute changes and transitions. ${ }^{18}$ Second, there is wide variation in the health care experiences and outcomes (eg, hospitalizations, physician visits) of older adults with chronic illness that are due to individual physiologic and functional determinants, as well as characteristics of the local social and physical environment, such as the concentration and distribution of hospitals and physicians in a defined area. Finally, chronic illness eventually leads to death, an event that is largely unanticipated but not unexpected. ${ }^{5}$ Older adults nearing the end of life with advanced disease often receive unwanted medical care and aggressive interventions that are at odds with their life situation and care preferences. ${ }^{24}$ More timely advance care planning and an emphasis on coordinated care among patients, providers, and families have been advocated as ways to lessen inappropriate treatment, ${ }^{25}$ but there has been limited empiric evidence to support many of these efforts. ${ }^{26}$

\section{The Traditional Medicare Program}

Fee-for-service Medicare is the major health care delivery model for older adults experiencing chronic illness in the United States. ${ }^{4}$ When first implemented in 1966, Medicare's coverage policies, benefits, and criteria for determining medical necessity were all directed to the treatment of acute, episodic illness, an orientation that continued until recently. ${ }^{9,27,28}$ For over 25 years, Medicare reimbursed for physicians' services based on each doctor's actual or customary fee for a service, or the prevailing fee in a geographic area, and Medicare payments to physicians subsequently grew at an average rate of more than $14 \% .^{3}$
Traditional Medicare provides a basic program of health insurance for adults who are 65 years of age and older. This program includes hospital insurance (Part A) covering inpatient care and skilled nursing care, in addition to home health care services, and supplemental health insurance (Part B) covering physician services and other outpatient care such as physical and occupational therapy. ${ }^{29}$ Hospice care is a benefit covered under Part A, and beneficiaries are eligible if they are certified to be terminally ill with a 6-month or less life expectancy and forego their routine Medicare-covered benefits for their illness. ${ }^{29}$

Although the Medicare program largely serves elders with chronic conditions, it has limited flexibility to impact the processes by which physicians, hospitals, and other health care entities provide care. ${ }^{4}$ From its roots in indemnity insurance, patient preference is a major economic driving force; Medicare beneficiaries are free to choose any health care provider as long as assignment is accepted. However, the downside of such patient flexibility is the duplication of services and the absence of coordinated care across providers and settings. ${ }^{4}$ Care episodes define the unit of reimbursement, and Medicare currently does not pay for care coordination or disease management services that are outside of these encounters. In addition, traditional Medicare does not provide an incentive to providers who practice evidence-based medicine, nor does it penalize those who do not. ${ }^{3}$

Despite the overriding need for coordinated and continuous care across multiple care settings and providers, traditional Medicare is organized around specific disease states and reimbursed according to episodes of care. ${ }^{30}$ The majority of Medicare spending is largely directed to beneficiaries with multiple diagnoses or comorbid conditions who require care from several institutions and providers; approximately two thirds of the program costs are attributable to $20 \%$ of beneficiaries with 5 or more chronic conditions. ${ }^{31,32}$ The existing system of feefor-service reimbursement indirectly contributes to the fragmentation and absence of coordinated health care resources across hospitals, physicians, and long-term care facilities, which is a hidden reason for the continued rise in health care costs. ${ }^{33}$

\section{Medicare Prescription Drug Improvement and Modernization Act of $\mathbf{2 0 0 3}$}

The MMA (P.L. 108-173) was an important first step in the reorientation of Medicare to chronic 
illness care. ${ }^{9}$ Although much attention has been given to the prescription drug benefit, ${ }^{34}$ there were several provisions in the MMA that were designed to improve the quality of care and reduce costs for chronically ill beneficiaries. ${ }^{21,35}$ Each of the provisions support pilot programs in chronic care that are budget neutral; spending in the pilot programs cannot exceed what would have been spent in the program's absence. ${ }^{21}$

Section 721 established the Chronic Care Improvement Program, a new covered service to improve the quality of care and reduce health care costs by promoting the coordination of care across providers, teaching beneficiaries self-care techniques, and encouraging the use of evidence-based treatment guidelines for 3 chronic conditions: complex diabetes mellitus, congestive heart failure, and chronic obstructive pulmonary disease. ${ }^{9,35}$ Contracts have been awarded for 9 pilot projects and contractors may propose monthly fees to cover the cost of disease management; however, they are required to save the program a minimum of $5 \%$ of overall health care costs. ${ }^{31}$

Success of the Chronic Care Improvement Program could eventually spur legislation to grant the federal agency responsible for Medicare, CMS, new authority to establish a bundled form of reimbursement for chronic illness case management programs. ${ }^{4}$ One prior reimbursement approach has been modeled after primary care case management programs in Medicaid recipients, where a designated primary care physician was paid a management fee or received a higher payment as the patient's care coordinator. ${ }^{4}$ Other organizational models have contracted directly with disease management firms, or with local agencies, such as health departments, as care coordinators. ${ }^{4}$

CMS's predecessor, the Health Care Financing Agency, had prior experience with evaluating alternative approaches to chronic care management in the 1990s when Congress mandated case management services for high-cost Medicare beneficiaries. ${ }^{4}$ Demonstration projects at that time were also disease-specific programs (eg, congestive heart failure) that were administered by a large insurer, a peer review organization, and a tertiary care teaching hospital. ${ }^{4}$ Although case management resulted in no reduction in costs or improvements in patient health behaviors or health outcomes, the project findings provided important lessons regarding the successful implementation of any new chronic care initiatives, such as those found in the MMA. ${ }^{36}$
There were 4 primary reasons cited why case management previously failed to impact Medicare spending and improve patient health outcomes. Physician resistance and lack of involvement was the primary reason of failure in these earlier projects. ${ }^{36}$ Both primary care and specialty physicians were major stakeholders in prior case management initiatives and physicians continuing to have often conflicting interests in a reconstituted Medicare program. Primary care physicians have the most to gain in adopting chronic illness management programs because such programs position them in the care coordinator role. ${ }^{37}$ On the other hand, medical specialists and other care providers who currently benefit from Medicare's current feefor-service payment structure may object to a perceived threat to their decision-making autonomy, in addition to potential reductions in reimbursement.

The absence of focused goals and interventions, and the lack of specific clinical knowledge and case management experience, were additional reasons for the prior failure of Medicare's case management approach. ${ }^{36}$ Quality of care is often determined by clinical practice guidelines, which uses process and outcome measures for specific diseases, such as congestive heart failure. Earlier Medicare case management demonstration projects relied on nurses who had limited experience as coordinators, operated without consistent patient education guidelines, and were displaced from the ongoing processes of patient care. ${ }^{36}$ Although the body of evidence-based guidelines has grown substantially in recent years, health care providers, particularly those from rural areas or in solo practice, may lack the financial resources or the organizational infrastructure to successfully implement some initiatives that enhance case management in outpatient practice, such as an electronic health record or a dedicated care coordinator.

The lack of financial incentives to reduce costs was the final reason cited for the earlier failure of case management among Medicare beneficiaries. ${ }^{36}$ The "pay-for-performance" initiative found in Section 649 of the MMA again takes up this issue. This section outlines a demonstration program to provide incentives for physicians to adopt and use health information technology and evidence-based outcome measures to stabilize medical conditions, minimize disease exacerbations, and reduce adverse outcomes. ${ }^{35}$ The concept of linking reimbursement to performance measures is controversial and the 
use of this approach has not been demonstrated. ${ }^{31,38}$ A recent study found that paying physicians to reach a common, fixed performance target produces little gain in quality and largely rewards those providers with higher performance at baseline. ${ }^{39}$

An additional, major limitation to a pay-forperformance approach is the lack of well-developed measures to determine the quality of care delivered to patients with multiple conditions. ${ }^{31}$ Quality of care is often based on measurable indices, such as the reliance on glycohemoglobin levels in diabetic patients, rather than meaningful, patient-centered measures to determine the quality of care. ${ }^{31}$ In older adults, quality-of-care measures target only a few medical conditions and often focus on mortality as a major outcome, ignoring other geriatric conditions and aspects of care (eg, patients' self-rated health or functional status) that are of equal or greater importance to these patients. ${ }^{40}$ Adjusting Medicare reimbursement based on limited quality measures has the potential for increasing costs and reducing the quality of patient care by: (1) increasing the use of specific laboratory tests; (2) redirecting physician attention away from coordination of care and clarification of patient preferences to meeting set quality metrics; and (3) discouraging physicians from caring for patients with complex conditions. ${ }^{31}$

\section{The Quality Improvement Roadmap and Road Ahead for Family Physicians}

CMS recently released the Quality Improvement Roadmap, outlining a vision for Medicare to be "the right care for every person every time" by "making care safe, effective, efficient, patient-centered, timely, and equitable." 10 The first part of the roadmap focuses on 5 major system strategies for improving care: (1) working through partnerships to improve performance and achieve specific quality goals; (2) developing and providing quality measures as a way to promote quality improvement efforts; (3) reimbursing in a way that rewards patientfocused, high-quality care; (4) assisting care providers in making care more effective, particularly through the use of electronic health systems; and (5) rapidly importing effective, evidence-based treatments into patient care. ${ }^{10}$ The second part of the roadmap links these system strategies to areas of opportunity having the greatest potential to improve quality and reduce health care costs, such as implementation of effective health information technology. ${ }^{10}$
How will Medicare's new emphasis impact the organization of care that family physicians and other primary care physicians provide to older adults with chronic illness? Quality is unambiguously the foundation of Medicare's movement to a program responsive to the chronic care needs of an older population. Family physicians will first need to strongly rethink their current delivery models of care, where competing patient demands during acute office encounters dominate the delivery of care. ${ }^{41}$ For example, one measurable quality goal, the rate of preventive services in primary care practice, remains below national goals. ${ }^{42}$

The New Model of Family Practice, described in the Future of Family Medicine project, provides a useful template for rethinking the practice of family medicine. By focusing on both quality and safety, the New Model promotes an ongoing examination of patient care data within the practice, the solicitation of patient feedback, and the use of a structured and ongoing administrative mechanism to measure characteristics of the practice and the patients under care there. ${ }^{43}$ Implementing such changes in a systematic fashion requires the use of quality-of-care measures that are salient to primary care, representing the quality of care for the whole person. ${ }^{44}$ For example, although older adults with chronic illness have multiple chronic conditions, ${ }^{31,32}$ most existing quality measures focus on single, disease-specific indicators, ${ }^{45}$ or measurable preventive service indices, such as mammogram screening or influenza vaccination. ${ }^{42}$ To satisfactorily gauge the quality of care provided in primary care settings, family physicians will need to promote the value of general health and functional status measures, ${ }^{46}$ as well as measures of the general processes of care as quality indices. ${ }^{44}$

Financial incentives effectively change the practice behavior of primary care physicians,${ }^{47}$ particularly when incentives are aligned with professional values and focused on a common clinical interest. ${ }^{48}$ Family physicians should closely follow a major experiment in the United Kingdom, where general practitioners entered into a contract with the $\mathrm{Na}$ tional Health Service in 2004 that will provide additional payments for the receipt of high-quality care; nearly one third of the physician's income will depend on achieving a complex set of quality and outcome indicators. ${ }^{49}$

Many physicians in the United States have had prior experience with quality incentives through 
managed care $^{38}$; however, a recent report from the Institute of Medicine calls for CMS to increase payments to providers who deliver high-quality care. ${ }^{50}$ Beyond managed care markets, current bipartisan support for tying changes in Medicare reimbursement to new requirements designed to promote the quality of physician care for chronic illness ${ }^{3}$ are signs of future fundamental changes in the ways that physicians will be compensated. ${ }^{51}$ It is quite possible that fee-for-service Medicare will be replaced in coming years with a reimbursement and organizational structure-focused quality chronic illness care. One proposed compensation model focuses on the institution of a risk-adjusted fee that would pay physician practices for serving as a "medical home" with responsibilities for delivering medical care, coordinating care across health venues, providing health education, and supporting family caregivers. ${ }^{31,43}$

\section{Final Comments}

After a long and tempestuous struggle, Medicare was enacted in 1965 and still remains an indemnity health insurance program that is the major driver of chronic illness care within the United States. ${ }^{29} \mathrm{Al}$ though several provisions for reorganizing chronic illness care in the MMA are ambitious, few demonstration programs have resulted in both cost savings and improved health outcomes, and it is the posture of the CMS to adopt incremental, rather than sweeping, change. ${ }^{31}$ Still, the major challenge for health care in the United States during the next several decades will be the reorganization and financing of a Medicare system that can meet the needs of older adults living with chronic illness. ${ }^{52}$ As providers of chronic illness care, family physicians need to be actively engaged in Medicare's reorientation by articulating and promoting a quality of care that effectively integrates evidence-based medicine with a person-centered focus.

\section{References}

1. Hing E, Cherry DK, Woodwell DA. National Ambulatory Medical Care Survey: 2003 summary. Advance data from vital health statistics; no 365 . Hyattsville (MD); US Department of Health and Human Services, Centers for Disease Control and Prevention, National Center for Health Statistics. 2005.

2. Champlin L. Speak out designed to prevent medicare payment cuts. American Academy of Family Physicians. Available from http://www.aafp.org/ x38554.xml?printxml. Accessed 10/7/2005.
3. Iglehart JK. Linking compensation to quality-medicare payments to physicians. N Engl J Med 2005; 353:870-2.

4. Berenson RA, Horvath J. Confronting the barriers to chronic care management in Medicare. Health Affairs 2003;W3-37-33-53.

5. Lynn J, Adamson DM. Living well at the end of life, adapting health care to serious chronic illness in old age. Santa Monica (CA): Rand Health; 2003.

6. Social Security and Medicare Board of Trustees. Status of the Social Security and Medicare programs. Washington (DC); 2003.

7. American Academy of Family Physicians. Practice profile survey I. American Academy of Family Physicians. Available from http://www.aafp.org/ x772.xml?printxml. Accessed 10/7/2005.

8. Eichner J, Blumenthal D, editors. Medicare in the 21st century: building a better chronic care system. Washington (DC): National Academy of Social Insurance; 2003.

9. Anderson GF. Medicare and chronic conditions. N Engl J Med 2005;353:305-9.

10. Center for Medicare and Medicaid Services. Quality improvement roadmap. Washington (DC); 2005.

11. National Center for Health Statistics. Health, United States, 2003. Hyattsville (MD): US Department of Health and Human Services; 2003.

12. Field MJ, Cassel CK. Approaching death. Washington (DC): National Academies Press; 1997.

13. Brim OG, Friedman HE, Levine S, Scotch NA. The dying patient. New York: Russell Sage Foundation; 1970.

14. Centers for Disease Control. Chronic disease overview. National Center for Chronic Disease Prevention and Health Promotion. Available from http://www. cdc.gov/nccdphp/overview.htm. Accessed 10/3/2003.

15. Jemal A, Ward E, Hao Y, Thun M. Trends in the leading causes of death in the United States, 1970 2002. JAMA 2005;294:1255-9.

16. Centers for Disease Control. Healthy aging: preventing disease and improving quality of life among older Americans. Atlanta (GA): Department of Health and Human Services, Centers for Disease Control; 2003.

17. Strauss AL, Corbin JM, Fagerhaugh BG, et al. Chronic illness and the quality of life, 2 Ed. St. Louis: Mosby; 1984.

18. Duncan GJ, Brooks-Gunn J, Yeung YW, Smith JR. How much does childhood poverty affect the life chances of children? Am Sociol Rev 1998;63:406-23.

19. Lunney JR, Lynn J, Hogan C. Profiles of older medicare decedents. J Am Geriatr Soc 2002;50:1108-12.

20. Fisher ES, Wennberg DE, Stukel TA, et al. The implications of regional variations in Medicare spending. Part 1 . The content, quality, and accessibility of care. Ann Intern Med 2003;138:273-87.

21. Mittler J. Medicare: making it a force for innovation 
and efficiency. New York: Commonwealth Fund; 2005.

22. Macintyre S, Ellaway A. Ecological approaches: rediscovering the role of the physical and social environment. In: Berkman LF, Kawachi I, editors. Social epidemiology. New York: Oxford University Press; 2000.

23. Fisher ES, Wennberg DE, Stukel TA, et al. The implications of regional variations in Medicare spending. Part 2. Health outcomes and satisfaction with care. Ann Intern Med 2003;138:288-98.

24. Lynn J, Goldstein NE. Advance care planning for fatal chronic illness: avoiding commonplace errors and unwarranted suffering. Ann Intern Med 2003; 138:812-8.

25. Teno JM, Lynn J. Putting advance-care planning into action. J Clin Ethics 1996;7:205-13.

26. Lorenz K, Lynn J, Morton SC, et al. End-of-life care and outcomes. Summary, Evidence Report/Technology Assessment No. 110. Rockville (MD): Agency for Healthcare Research and Quality; 2004.

27. Corrigan JM, Eden J, Smith BM. Leadership by example: coordinating government roles in improving healthcare quality. Washington (DC): National Academies Press; 2003.

28. Williams RD. The unique needs of Medicare beneficiaries. Brief no. 10. Washington (DC): National Academy of Social Insurance; 2004.

29. Medicare. Medicare Plan Choices. Centers for Medicare and Medicaid Services. Available from http://www. medicare.gov/Choices/Overview.asp. Accessed 4/1/2004.

30. Rothman AA, Wagner EH. Chronic illness management: what is the role of primary care?. Ann Intern Med 2003;138:256-61.

31. Wolff JL, Boult C. Moving beyond round pegs and square holes: restructuring Medicare to improve chronic care. Ann Intern Med 2005;143:439-45.

32. Partnership for Solutions. Medicare: cost and prevalence of chronic conditions. Baltimore (MD): Johns Hopkins University Press; 2002.

33. Shortell SM, Gillies RR, Anderson RA, et al. Remaking health care in America: building organized delivery systems. San Francisco (CA): Jossey-Bass; 1996.

34. Frank RG. Election 2004: prescription drug prices. N Engl J Med 2004;351:1375-7.

35. Centers for Medicare and Medicaid Services. CMS demonstration projects under the Medicare Modernization Act. US Department of Health and Human Services. Available from http://www.cms.hhs.gov/ researchers/demos/MMAdemolist.asp. Accessed 10/ $11 / 2005$.

36. Schore JL, Brown RS, Cheh VA. Case management for high-cost Medicare beneficiaries. Health Care Financing Review 1999;20:87-101.

37. American Academy of Family Physicians. Testimony on "medicare chronic disease" care management fee concept before the practicing physicians' advisory council. Available from http://www.aafp.org/ x26272.xml?printxml. Accessed 4/7/2004.

38. Rosenthal MB, Fernandopulle R, Song HR, Landon B. Paying for quality: providers' incentives for quality improvement. Health Aff 2004;23:127-41.

39. Rosenthal MB, Frank RG, Li Z, Epstein AM. Early experience with pay-for-performance. JAMA 2005; 294:1788-93.

40. Wenger NS, Solomon DH, Roth CP, et al. The quality of medical care provided to vulnerable community-dwelling older patients. Ann Intern Med 2003;139:740-7.

41. Crabtree BF, Miller WL, Tallia AF, et al. Delivery of clinical preventive services in family medicine offices. Ann Fam Med 2005;3:430-5.

42. Pham HH, Schrag D, Hargraves JL, Bach PB. Delivery of preventive services to older adults by primary care physicians. JAMA 2005;294:473-81.

43. Future of Family Medicine Leadership Project. The future of family medicine: a collaborative project of the family medicine community. Ann Fam Med 2004;2:S3-32.

44. Stange KC. The paradox of the parts and the whole in understanding and improving general practice. Int J Qual Health Care 2002;14:267-8.

45. Intensive blood-glucose control with sulphonylureas or insulin compared with conventional treatment and risk of complications in patients with type 2 diabetes (UKPDS 33). Lancet 1998;352:837-53.

46. Stewart AL, Greenfield S, Hays RD, et al. Functional status and well-being of patients with chronic conditions. Results from the Medical Outcomes Study. JAMA 1989;262:907-13.

47. Gosden T, Forland F, Kristiansen IS, et al. Impact of payment method on behaviour of primary care physicians: a systematic review. J Health Serv Res Policy 2001;6:44-55.

48. Spooner A, Chapple A, Roland M. What makes British general practitioners take part in a quality improvement program? J Health Serv Res Policy 2001;6:145-50.

49. Roland M. Linking physicians' pay to the quality of care-a major experiment in the United Kingdom. N Engl J Med 2004;351:1448-54.

50. Institute of Medicine. Leadership by example: coordinating government roles in improving health care quality. Washington (DC): National Academies Press; 2002.

51. Epstein AM, Lee TH, Hamel M. Paying physicians for high-quality care. N Engl J Med 2004;350:406-10.

52. United States Senate Special Committee on Aging. Developments in aging: 1999 and 2000. Washington (DC): US Senate, 107th Congress; 2001. 